\title{
O OLIVINA LEUCITITO DE PÂNTANO E A NATUREZA DO VULCANISMO DA FORMAÇÃO MATA DA CORDA, MG
}

\author{
JOSÉ CARUSO MORESCO DANNI* e ANDRÉ A. SCARTEZINI*
}

\begin{abstract}
THE OLIVINE LEUCITITE OF PÂNTANO AND THE NATURE OF THE VOLCANISM OF MATA DA CORDA FORMATION, MG. Petrographic and chemical features of the olivine leucitite from Pântano, western Minas Gerais, are described and compared with other leucite-bearing volcanics in Brazil (e.g. Lagoa Formosa, Sacramento and Amorindpolis). The primary mineral assemblage of the Pântano rocks comprises olivine, leucite, titanian magnetite, clinopyroxene, melilite, perovskite, phlogopite and apatite. The main deuteric products are: barite, zeolite, calcite, serpentine and clay minerals. Chemically the rocks are typically ultrabasic $(36 \%-40 \% \mathrm{SiCh})$ and ultrapotassic $\left(\mathrm{K}_{2} \mathrm{O}>2 \%, \mathrm{~K} / \mathrm{Na}>10\right)$ with very high $\mathrm{TiOi}(5.0 \%-6,5 \%)$ and $\mathrm{CaO}+\mathrm{MgO}(28 \%-30 \%)$ contents. These characteristics indicate that the major volcanic contribution of the Mata da Corda Formation is of kamafugitic composition, very similar to the Toro Ankole type rocks. Compositional and temporal relations of this volcanism with the lamproitic and kimberlitic rocks of the region have yet to be established.
\end{abstract}

Keywords: Petrology, Chemistry, leucitite volcanism, Mata da Corda Formation, Brazil.

\begin{abstract}
RESUMO Neste estudo são descritas as características petrográficas e químicas do olivina leucitito do neck vulcânico de Pântano, e comparadas com outras ocorrências de rochas vulcânicas leucitíticas (e.g. Lagoa Formosa, Sacramento e Amorinópolis). O leucitito de Pântano é formado pela seguinte associação mineral: olivina (Fo 88\%), leucita, magnetita com Ti, clinopiroxênio (augita-salita), melilita (akermanita) perovskita, flogopita e apatita. Seus principais minerais deutéricos são: barita, calcita, zeolitas, serpentinas e argilo-minerais. Quimicamente, este magmatismo é de natureza francamente ultrabásica (SiÓ2 36\%-40\%), ultrapotássico $\left(\mathrm{K}_{2} \mathrm{O}>2 \%\right.$ e $\left.\mathrm{K} / \mathrm{Na}>10\right)$ com teores muito altos em $\mathrm{TiO}_{2}(5,0 \%-6,5 \%)$ e em $\mathrm{CaO}+\mathrm{MgO}$ $(28 \%-30 \%)$. Estas feições indicam que o magmatismo é de composição kamafugftica, muito similar ao da região de Toro Ankole (Uganda). As relações temporais e composicionais destas rochas com os lamproítos e kimberlitos que ocorrem na região são assuntos ainda desconhecidos.
\end{abstract}

Palavras-chaves: Petrologia, química, vulcanismo leucititfco, Formação Mata da Corda, Brasil.

INTRODUÇÃO O Fácies Patos da Formação Mata da Corda (Ladeira et al. 1971) ocupa uma área de cerca de 2.200 $\mathrm{km}^{2}$, estendendo-se ao longo do flanco ocidental da zona de arqueamento do Alto Paranaíba. Nos tempos do Cretáceo Superior, a sua distribuição areai ultrapassava em muito seus atuais limites, como comprovam a ocorrência de inúmeros focos vulcânicos e de testemunhos erosivos por uma grande extensão regional. Na região do Planalto da Mata de Corda este fácies compreende um diversificado conjunto de rochas vulcânicas (lavas, tufos, aglomerados e rochas epiclásticas), com espessura máxima de $180 \mathrm{~m}$ (Ladeira \& Brito 1968). Em toda a área de ocorrência, os depósitos tefraícos são predominantes, atestando assim o caráter essencialmente explosivo do vulcanismo. De acordo com Seer \& Moraes (1988), os derrames de lavas tornam-se mais freqüentes nas porções superiores do fácies.

Apesar de constituir um dos mais notáveis exemplos de vulcanismo alcalino intracontinental, a sucessão e a natureza dos seus diversos pulsos vulcânicos, bem como as suas características petrográficas e geoquímicas, não são suficientemente conhecidas. A generalizada incidência de alterações deutéricas e a grande susceptibilidade de suas rochas ao intemperismo, constituem verdadeiros óbices ao desenvolvimento de estudos mineralógicos e geoquftnicos (Guimarães 1955). Nesse contexto, o estudo da ocorrência de Pântano e sua correlação com outros focos vulcânicos vem adicionar novos dados sobre a natureza do vulcanismo da Mata da Corda. Com relação e esse aspecto, embora tenham sido reconhecidas composições do tipo melteigfticas (Barbosa et al. 1970), a maioria dos dados (Guimarães 1955, Murta 1966, Ladeira \& Brito 1968, Moraes et al. 1987) Indica que o vulcanismo foi de natureza kamafugítica. Ademais, é notável salientar a estreita vinculação espacial e temporal dessas rochas com kimberlitos
(Svisero et al. 1979, 1984, Gonzaga \& Tompkins 1988, Tompkins \& Gonzaga 1989) e com lamproítos (Leonardos \& Ulbrich 1987) reconhecidos na região.

O Conduto Vulcânico de Pântano A intrusão de Pântano foi identificada por Barbosa et al. (1970) como sendo um neck vulcânico de composição olivina-basalto. A sua idade foi determinada por Hasui \& Cordani (1968), por meio do método $\mathrm{K} / \mathrm{Ar}$, como sendo de 77,9 $\pm 3,9 \mathrm{Ma}$.

Regionalmente, o conduto vulcânico de pântano localiza-se na porção mediana de um lineamento tectono-magmático, que baliza a distribuição dos condutos vulcânicos da região de Lagoa Formosa (Moraes et al. 1987), parte do curso do Rio Paranaíba e outras intrusões menores (Fig. 1). O conduto dista cerca de $10 \mathrm{~km}$ a norte do povoado homônimo e está alojado em filitos e quartzitos pertencentes à Formação Canastra; em superfície, apresenta forma grosseiramente elíptica, com eixos de $700 \mathrm{~m} \times 250 \mathrm{~m}$, e ocupa uma área de $0,17 \mathrm{~km}^{2}$. No interior da estrutura e em meio a um espesso solo argiloso, afloram blocos isolados de olivina leucititos e blocos métricos de silexitos - estes, representando restos de teto da intrusão. Os efeitos de contato sobre os filitos limitam-se a perturbações locais nas atitudes das foliações e a ocorrência de zonas de silicificação de origem hidrotermal.

O Olivina Leucitito Corresponde a uma rocha de textura microporfirítica, rica em xenocristais de olivina e em nódulos subarredondados, com dimensões entre $0,5 \mathrm{~cm}$ a $3 \mathrm{~cm}$, de natureza dunítica. Os xenocristais de olivina resultam de desagregação dos nódulos e mostram feições internas resultantes de deformações produzidas em regime dúctil, como planos de deslizamentos, extinções ondulantes e kinks. Neles, são comuns as formas arredondadas e com golfos de corrosão, o que 


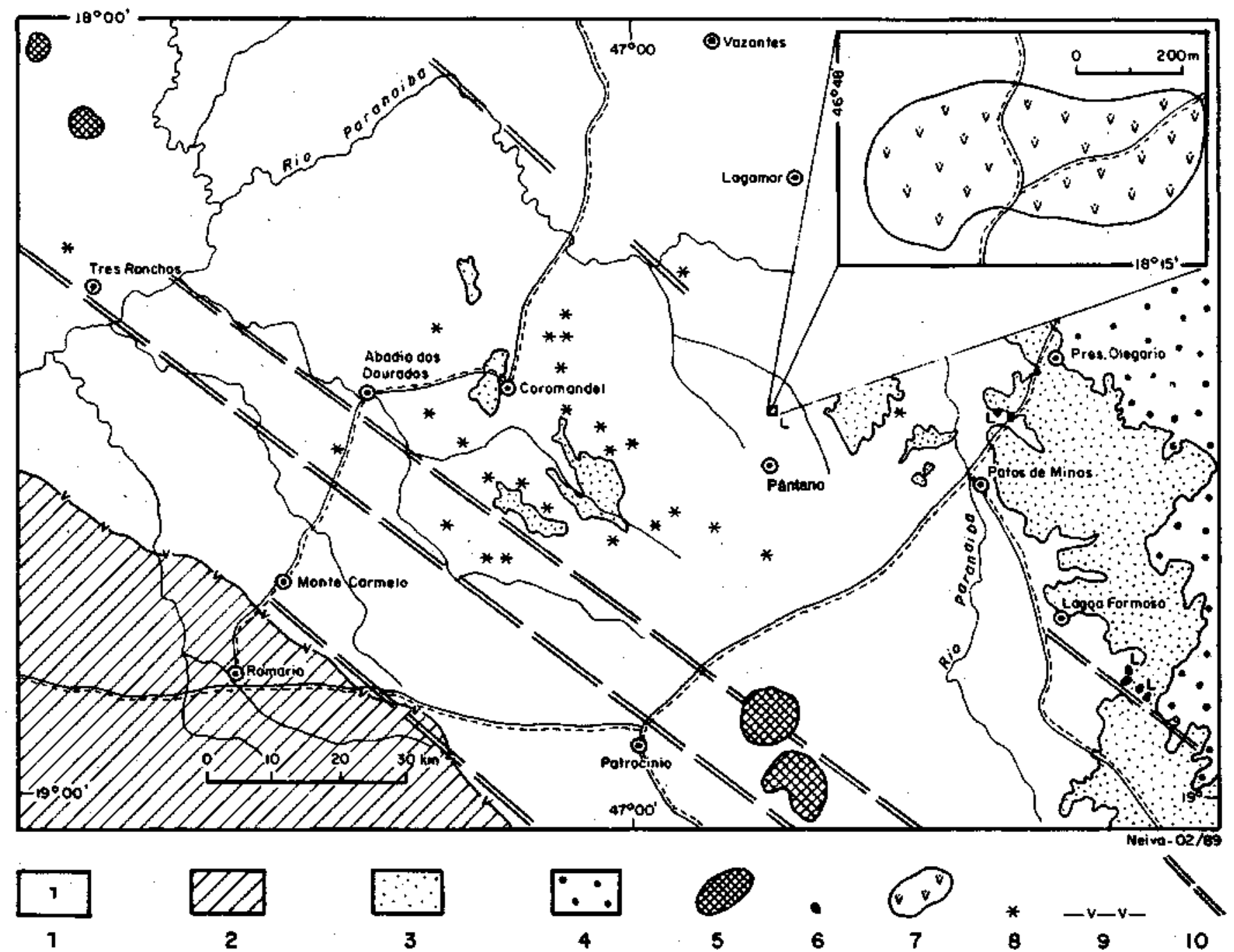

Figura 1-Localização da intrusão de Pântano: 1. terrenos pré-cambrianos; 2. Bacia do Paraná; 3. Formação Mata da Corda; 4. Formação Areado; 5. Complexos ultramáficos-carbonatíticos; 6. Condutos leucitíticos; 7. Intrusão de Pântano; 8. Pipes kimberliticos; 9. Limite da Formação Serra Geral; 10. Lineamento tectônico

Figure 1 - Localization of the Pântano intrusion: 1. Precambrian terrains; 2. Paraná Basin; 3. Mata da Corda Formation; 4. Areado Formation; 5. Ultramafite-carbonatite complexes; 6. Leucitite pipes; 7. Pântano intrusion; 8. Kimberlite pipes; 9. Limit of the Serra Geral Formation; 10. Tectonic lineaments

testemunha a ulterior instabilidade desses cristais no líquido magmático. Quanto a origem, os nódulos duníticos podem ser interpretados como resultantes da segregação de olivina durante a fusão mantélica (nódulos residuais), ou como cumulados derivados de um magma de composição olivina leucitito, fracionado em condições crustais. Além destes, são freqüentes nódulos enalogênicos, constituídos de fragmentos de até $5 \mathrm{~cm}$ de silexitos e quartzitos.

A matriz que envolve estes fragmentos corresponde ao olivina leucitito propriamente dito. Ela possui textura microporfirítica, caracterizada por conter cristais zonados de olivina (Fo 88\%), de perovskita, de magnetita de $\mathrm{Cr}$-Ti e cristais globulares de leucita (alterados para zeolitas). Em conjunto, estes minerais encontram-se envolvidos por uma massa intersticial muito fina, formada por agregados de lamelas de flogopita, prismas de clinopiroxênio, cristais quadráticos de melilita (akermanita), granules de magnetita com $\mathrm{Ti}$ e espinélio de $\mathrm{Cr}$, agulhas de apatita e de barita, além de massas e pseudomorfos compostos de serpentina, zeolitas, calcita e argilominerais.
As composições modais do olivina leucitito encontram-se expressas na tabela 1 .

Com base nestas características petrográficas, pode-se concluir que a cristalização da intrusão ocorreu em duas etapas. A primeira, de mais alta pressão, conduziu à geração precoce de olivina dos nódulos e a segunda, já no sítio da. intrusão, conduziu à formação da associação olivina+leucita + magnetita + perovskita, seguida de diopsídio+melilita-f flogopita.

De acordo com Foley (1985), este tipo de fracionamento (ol-le-cr-sp-cpx) pode ser explicado pelo aumento da fugacidade de oxigênio durante a cristalização (isto é, com rebaixamento da temperatura) de um líquido olivina leucitítico contendo baixas concentrações de $\mathrm{Cr}_{2} \mathrm{O}_{3}$ (por exemplo, $31 \mathrm{ppm}$ ).

Composições Normativas Os resultados das normas CIPW (Tab. 3) evidenciam as seguintes características para os olivinas leucititos de Pântano:

- Os minerais sálicos totalizam $18 \%$ e $20 \%$, enquanto os ca- 
Tabela l-Composição modal de leucitito de Pântano Table 1 - Modal composition of die Pântano leucitíte

\begin{tabular}{lrr}
\hline Olivina & $10,6 \%$ & $14,2 \%$ \\
Serpentina & $9,9 \%$ & $10,4 \%$ \\
Magnetita & $4,3 \%$ & $3,3 \%$ \\
Olivina total & $24,8 \%$ & $27,9 \%$ \\
Leucita & $12,1 \%$ & $13,9 \%$ \\
Espinclios & $10,4 \%$ & $8,5 \%$ \\
Perovskita & $6,4 \%$ & $5,9 \%$ \\
Melilita & $3,1 \%$ & $2,8 \%$ \\
* Mat. Intersticial & $43,1 \%$ & $41,0 \%$ \\
\hline
\end{tabular}

fêmicos correspondem a cerca de $60 \%$ e os óxidos $18 \%$ e $20 \%$, valores que expressam o caráter nitidamente máfico destes leucititos. O aparecimento de an e cs, nessas composições, materializa o relativo excesso de $\mathrm{Ca}$ e $\mathrm{Al}$ que mineralogicamente se expressa pela ocorrência de akermanita, perovskita, calcita e pela molécula de Tschermak do clinopiroxênio. - Ao se usar um terço do $\mathrm{TiO}_{2}$ total para fabricação de perovskita antes de ilmenita, as composições normativas adquirem valores mais realistas (Tab. 3/1* e $2 *$ ). Por outro lado, se $\mathrm{CO}_{2}$ é considerado no cálculo, a formação de calcita conduz a um grande aumento nas proporções de ol, an e ab, tornando a norma de composição basanítica. Conclui-se, por isso, que a calcita existente nesses leucititos é de origem deutérica e não uma fase liquidus.

Na tabela 2, constam as composições de outras lavas leucitíticas, as quais apresentam notáveis semelhanças com as de Pântano.

Tabela 2 -. Análises químicas de leucititos: le 2. Pântano; 3,4 e 5. Lagoa Formosa (Moraes et al. 1987); 6. Sacramento (Murta 1966); 7. Amorínópolis (Danni 1985) Table 2 - Chemical analyses of Brasilian leucitites: 1. and 2. Pântano; 3 , 4 and 5. Lagoa Formosa (Moraes et al. 1987); 6. Sacramento (Murta 1966); 7. Amorinópolis (Danni 1985)

\begin{tabular}{|c|c|c|c|c|c|c|c|}
\hline OXIDOS & 1 & 2 & 3 & 4 & 5 & 6 & 7 \\
\hline $\mathrm{SiO}_{2}$ & 34,63 & 32,97 & 34,08 & 39,06 & 39,33 & 39,37 & 36,38 \\
\hline $\mathrm{TjO}_{2}$ & 5,08 & 5,88 & 6,51 & 6,00 & 5,06 & 4,20 & 5,76 \\
\hline $\mathrm{Al}_{2} \mathrm{O}_{3}$ & 5,47 & 4,24 & 6,56 & 6,76 & 5,63 & 5,36 & 6,21 \\
\hline $\mathrm{Fe}_{2} \mathrm{O}_{3}$ & 4,98 & 5,02 & 6,26 & 4,99 & 4,96 & 4,91 & 5,79 \\
\hline $\mathrm{FeO}$ & 8,07 & 8,11 & 11,28 & 8,08 & 8,02 & 7,96 & 9,40 \\
\hline $\mathrm{MnO}$ & 0,20 & 0,21 & 0,32 & 0,18 & 0,17 & 0,37 & 0,21 \\
\hline $\mathrm{MgO}$ & 20,22 & 19,07 & 9,85 & 17,06 & 18,30 & 25,70 & 15,80 \\
\hline $\mathrm{CaO}$ & 9,59 & 10,47 & 15,48 & 9,05 & 10,51 & 6,55 & 11,90 \\
\hline $\mathrm{Na} 2 \mathrm{O}$ & 0,21 & 0,21 & 0,29 & 0,92 & 0,63 & 0,71 & 1,71 \\
\hline $\mathrm{K}_{2} \mathrm{O}$ & 2,07 & 2,36 & 3,35 & 2,27 & 1,61 & 2,70 & 3,62 \\
\hline & 0,55 & 0,57 & 1,85 & 0,20 & 0,04 & 0,56 & 0,81 \\
\hline $\mathrm{CO}_{2}$ & 2,45 & 2,94 & - & - & - & - & - \\
\hline PF & 5,43 & 6,51 & 1,07 & 5,60 & 4,93 & 2,10 & 1,75 \\
\hline TOTAL & 98,95 & 98,56 & 96,90 & 100,17 & 101,22 & 100,49 & 99,34 \\
\hline Mg val,* & 61,45 & 59,97 & 36,62 & 57,24 & 57,36 & 66,75 & 51,63 \\
\hline
\end{tabular}

* $\mathrm{MgO} \times 100 \mathrm{MgO}+\mathrm{FeO}_{\text {TOT }}+\mathrm{MnO}$

Características Químicas Com base na variação dos elementos maiores, Sahama (1974) subdividiu as rochas vulcânicas leucitíticas em duas séries: kamafugitos e orenditos (= lamproítos). Barton (1979), integrando dados mineralógicos e químicos, distinguiu três grupos, correspondentes às áreas tipo de Toro Ankole (constituída de kamafugitos), de Leucita Hills (representada por lamproítos) e de Viço, na Província Romana
Tabela 3-Composições normativas (cf. Tab. 2); nos cálculos $\mathrm{FeO} / \mathrm{Fe}^{\wedge}$ Ostfoi normalizado para 1.66

Table 3 - Normativa compositions of Brazilian leucitites (cf. Tab. 2) $\mathrm{FeO} / \mathrm{Fe}_{2} \mathrm{O}_{3}$ normalized to 1,66

\begin{tabular}{cccccccccc} 
& 1 & $1^{*}$ & 2 & $2^{*}$ & 3 & 4 & 5 & 6 & 7 \\
\hline ab & - & - & - & - & - & 1,53 & 0,15 & - & - \\
an & 8,64 & 8,70 & 4,08 & 4,39 & 13,91 & 8,05 & 8,25 & 3,52 & - \\
of & - & - & - & - & - & 14,19 & 10,09 & 5,86 & - \\
le & 10,53 & 10,05 & 12,20 & 13,13 & 15,78 & - & - & 8,12 & 17,19 \\
of & 1,06 & 1,01 & 1,07 & 1,13 & 1,35 & 3,63 & 2,98 & 3,31 & 6,54 \\
c & - & - & - & - & - & - & - & - & 2,42 \\
di & 23,70 & 22,62 & 21,54 & 15,38 & 18,60 & 29,70 & 36,64 & 20,22 & 17,58 \\
ol & 33,25 & 35,99 & 31,33 & 33,84 & 15,40 & 22,71 & 23,96 & 42,32 & 25,62 \\
c\$ & 2,91 & 3,53 & 7,71 & 8,83 & 8,81 & - & - & - & 10,13 \\
mt & 7,93 & 7,53 & 8,12 & 8,79 & 9,23 & 7,75 & 7,73 & 7,24 & 7,39 \\
il & 10,59 & 6,71 & 12,46 & 8,92 & 12,57 & 12,05 & 10,29 & 8,11 & 11,21 \\
op & 1,43 & 1,35 & 1,51 & 1,65 & 4,45 & 0,50 & 0,10 & 1,35 & 1,91 \\
pv & - & 3,01 & - & 4,00 & - & - & - & - & - \\
\hline
\end{tabular}

(formada por leucititos). As duas primeiras são associações típicas de vulcanismo em domínio de intraplaca continental, enquanto que a de Viço está relacionada a ambientes de consumo litosférico.

Mais recentemente, Foley et al. (1987), com base em maior número de análises e no comportamento e abundância dos elementos Terras Raras e outros elementos incompatíveis (U, $\mathrm{Th}, \mathrm{Zr}, \mathrm{Ba}, \mathrm{Sr}$ ), definiram novos campos composiconais para as rochas vulcânicas ultrapotássicas. Como critério inicial, excluiram da classificação os kimberlitos e todas as rochas com menos de $3 \%$ de $\mathrm{K}_{2} \mathrm{O}$. Com base neste critério, a maioria das rochas incluídas na tabela 2 não teria caráter ultrapotássico. Tomado isoladamente, este critério não é válido, posto que desconsidera a natureza ultrabásica de alguns tipos de rochas leucitíticas, como é o caso das vulcânicas da Mata da Corda, de Sacramento e de Amorinópolis.

Ainda conforme esses autores, as rochas ultrapotássicas devem apresentar valores de $\mathrm{K}_{2} \mathrm{O} / \mathrm{Na}_{2} \mathrm{O}>3$, o que é efetivamente verificado nos exemplos estudados, já que esta razão permanece em torno de 10. Apesar de ser um bom índice discriminante com relação ao caráter essencialmente potássico do vulcanismo, ele deve ser considerado com reservas, principalmente nas rochas com baixas concentrações em $\mathrm{K}_{2} \mathrm{O}$ e que apresentam evidências de alterações tardi-magmáticas. Tal é o caso das rochas da Mata da Corda, pois $\mathrm{K}_{2} \mathrm{O}$ varia entre 2,0\% e $3,6 \%$ e a soma dos álcalis varia entre $2,2 \%$ e $5,1 \%$, e há generalizada zeolitização, analcitização e carbonatação de leucitas e de suas frações vítreas.

Apesar dessas limitações, as características composicionais das rochas de Pântano, assim como das regiões de Lagoa Formosa, Sacrameno e Amorinópolis, são análogas às dos kamafugitos de Toro Ankole, distinguindo-se destas por apresentarem maior abundância em $\mathrm{TiO}_{2}$, coexistente com valores normais de $\mathrm{K}_{2} \mathrm{O}$ e $\mathrm{Al}_{2} \mathrm{O}_{3}$ (Figs. 2,3 e 4). Nas rochas de Pântano, pode-se verificar por meio de microscopia eletrônica de varredura, que a distribuição de $\mathrm{K}$ e $\mathrm{Al}$ no interior de cristais alterados de leucita apresenta fortes heterogeneidades, resultante da grande mobilidade desses elementos durante os processos de alterações deutéricas da leucita. Por outro lado, considerando a menor susceptibilidade à alteração das fases que contêm titânio e os valores consistentemente altos deste elemento, conclui-se que este é um aspecto original do vulcanismo da Formação Mata da Corda, feição que o distingue dos kamafugitos de Toro Ankole.

Quando consideradas as variações recíprocas entre $\mathrm{K}_{2} \mathrm{O}$ $\mathrm{Al}_{2} \mathrm{O} 3-\mathrm{TiO}_{2}$ (Fig. 5), as composições dessas rochas se situam no campo dos kimberlitos micáceos, que são relativamente mais ricos em $\mathrm{TiO}_{2}$ do que os kamafugitos-da área tipo. Esse 

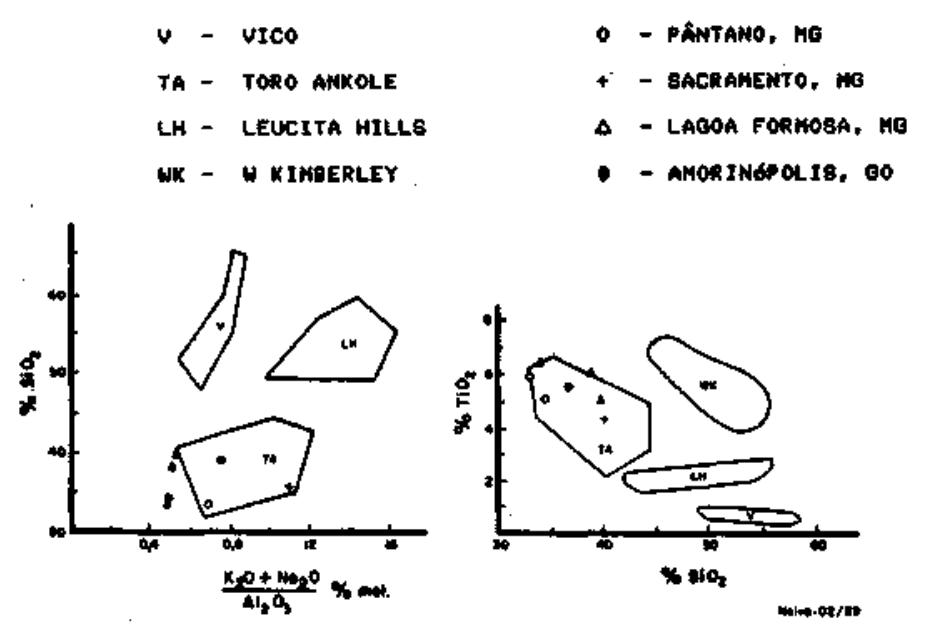

Figura 2 - Canpos composicionats das rochas vulcánicas leucifficas (Baton 1979)

Figure 2 - Compositional fiolds of the leacitita (barton 1979)
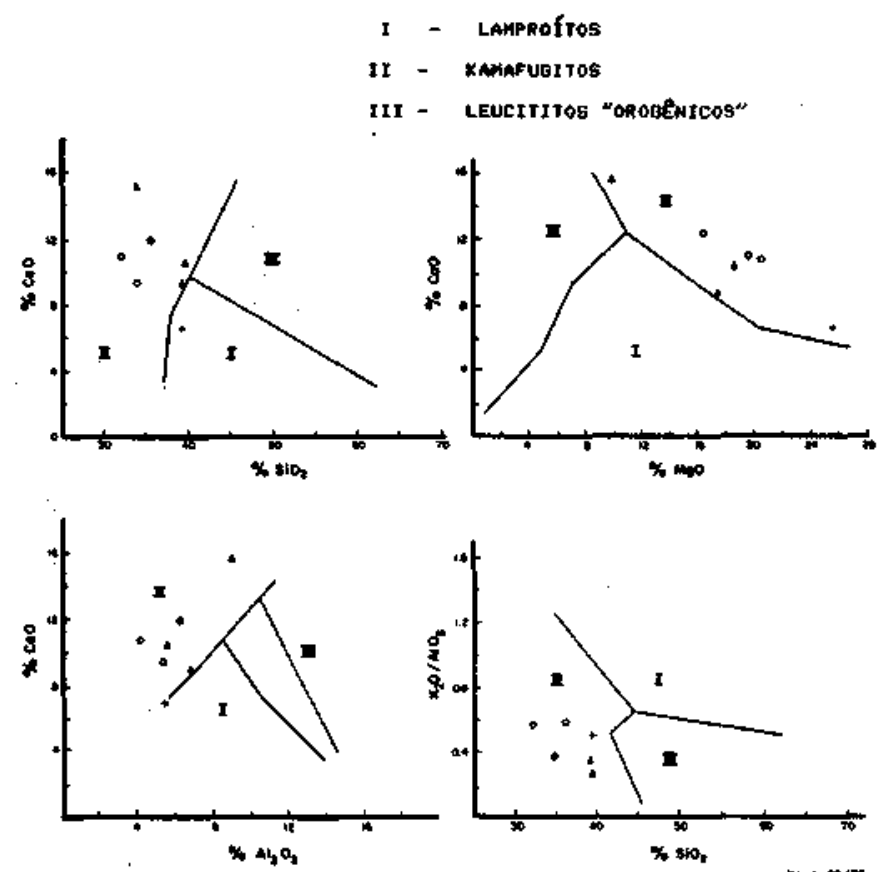

Figtora 3 - Domfnilas composicionais das rochas ultapotdsscas (modificudo de Foley et al, 1987)

Figure 3 - Compooitional fields of the ultra-potassic rocks (modified ifter Foley et al, 1987 )

desvio composicional exemplifica a maior concentração em $\mathrm{TiO}_{2}$ nas rochas estudadas, uma vez que os seus teores em $\mathrm{A}_{2} \mathrm{C} \gg 3$ e $\mathrm{K}_{2} \mathrm{O}$ não condizem com os encontrados nos kimberlitos micáceos (Alibert \& Albarede 1988). Nesse sentido, poder-se-ia enquadrá-los na categoria de kamafugitos com alto Ti.

Quanto aos demais parâmetros $\left(\mathrm{K}_{2} \mathrm{O}>2 \%\right.$, $\mathrm{K}_{2} \mathrm{O} / \mathrm{Al}_{2} \mathrm{O}_{3}=0,4, \mathrm{~K}_{2} \mathrm{O} / \mathrm{Na}_{2} \mathrm{O}=10, \mathrm{MgO}=19,5 \%, \mathrm{CaO}=10 \%$ e $\left.\mathrm{P}_{2} \mathrm{O}_{5} / \mathrm{TiO}_{2}<0,5\right)$, apresentam notável concordância com os kamafugitos de Toro Ankole (Pouclet 1980, Foley et al. 1987).

Discussão e Conclusões Os dados coligidos neste estudo confirmam a importância do magmatismo leucitítico na edificação do Fácies Patos da Formação Mata da Corda. A natureza kamafugftica do vulcanismo $\&$ mineralogicamente evidenciada pela associação olivina, perovskita, espinćlio de Cr, diopsidio, melitita \& flogopita. Kalsilita, mineral típico da
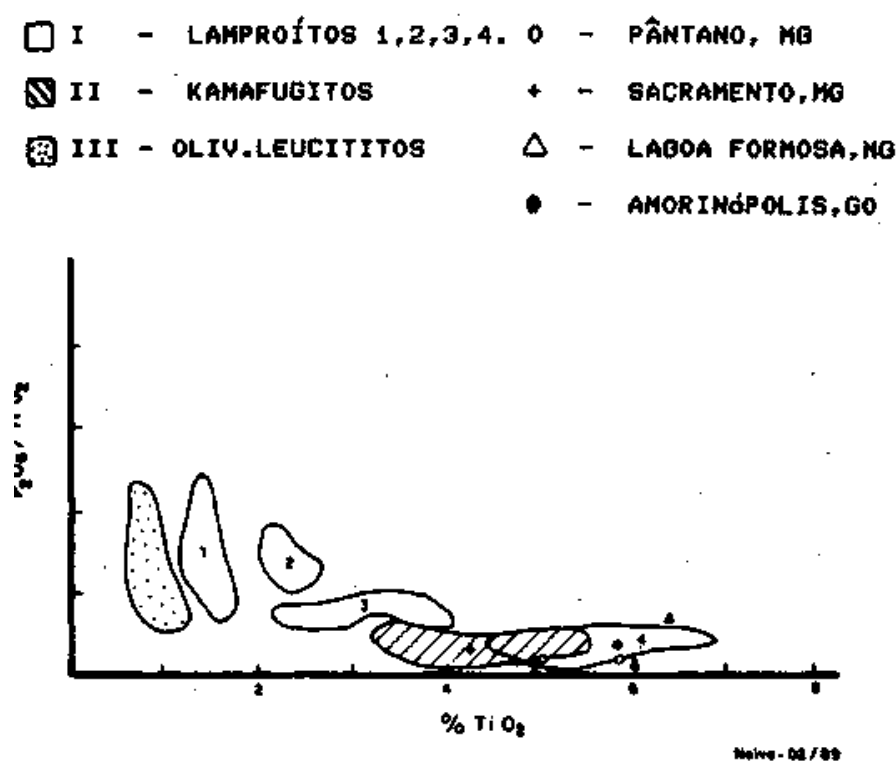

Figura 4-Variação $\mathrm{TiO} 2 \times \mathrm{TiO}_{2} / \mathrm{P}_{2} \mathrm{O}_{5}$ em rochas ultrapotâssicas (modificado de Foley et al. 1987): 1. SE da Espanha; 2. Leucita Hills EUA; 3. Gausberg. Ant.; 4. W. Kimberley, Austrália.

Figure $4-\mathrm{TiO}_{2} \times \mathrm{TiO}_{2} / \mathrm{P}_{2} \mathrm{O}_{5}$ diagram of the ultrapotassic rocks (modified after Foley et al. 1987): 1. SE Spain; 2. Leucita Hills EUA; 3. Gausberg, Antártica; 4. W. Kimberley, Austrália.

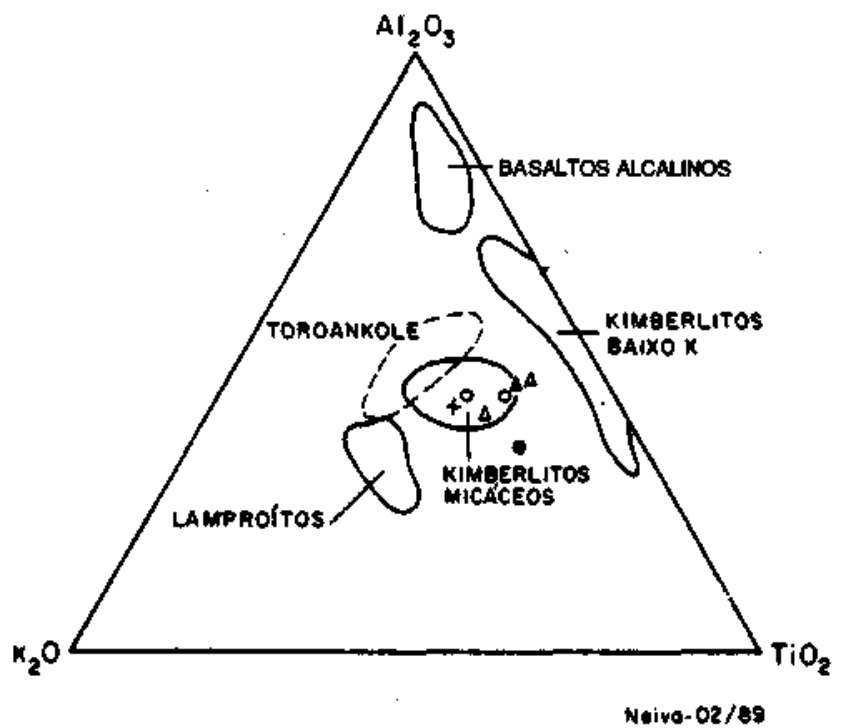

Figura 5 - Posição dos olivina leucititos brasileiros no diagrama $\mathrm{K}_{2} \mathrm{O}-\mathrm{Al}_{2} \mathrm{O} 3-\mathrm{TiO}_{2}$ (Alibert \& Albarede 1988). Símbolos, na figura 2

Figure $\mathrm{S}$ - Position of the Brazilian leucitites in the $\mathrm{K}_{2} \mathrm{O}-\mathrm{Al}_{2} \mathrm{O}_{3}-\mathrm{TiO}_{2}$ diagram (Alibert and Albared 1988). Symbols as in figure 2

associação, não foi identificado, provavelmente por ocorrer junto ao material intersticial, usualmente muito alterado. Com base nos principais parâmetros químicos, a rocha caracteriza-se por apresentar, em média: a. baixos teores de $\mathrm{SiO}_{2}$ $(\cong 40 \%), \mathrm{Al}_{2} \mathrm{O}_{3}(\cong 5,5 \%)$ e $\mathrm{Na}_{2} \mathrm{O}(\cong 1,0 \%) ;$ b. altos teores em $\mathrm{CaO}(\cong 10,0 \%), \mathrm{MgO}(\cong 20,0 \%), \mathrm{TiO}_{2}(\cong 5,5 \%)$ e $\mathrm{K}_{2} \mathrm{O}(2 \%$ $3,6 \%$; ; e c. altas concentrações de $\mathrm{Ba}, \mathrm{Rb}, \mathrm{Sr}, \mathrm{Nb}, \mathrm{Zr}$ e Tr le- 
vês (Ladeira \& Brito 1968, Moraes et al 1987).

Esse conjunto de características e mais o valor $\mathrm{Mg}-60, \mathrm{Ni}$ $>300$ ou $\mathrm{Cr}>200$ ppm, é indicativo de líquidos magmáticos primitivos gerados em profundidades de 100 ou mais quilômetros, sob condições mantélicas especiais (discussão em Foleyetal. 1987).

A geração de líquidos kamafugíticos primários implica na existência de um manto do tipo granada lherzolito, relativamente enriquecido em $\mathrm{Mg}$ e $\mathrm{Ca}$ (com respeito a $\mathrm{Na}$ e $\mathrm{AI}$ ), e em elementos como $\mathrm{K}, \mathrm{Sr}, \mathrm{Ba}, \mathrm{Ti}, \mathrm{Rb}, \mathrm{Zr}, \mathrm{Nb}$, e TR leves, os quais presumivelmente estariam fixados em minerais de origem metassomática (flogopita, richterita de K) ou em acessórios do tipo titanatos de $\mathrm{Ba}$ e $\mathrm{Sr}$. Um tal manto, submetido a taxas de fusão parcial inferiores a $5 \%$, em presença de uma fase fluida rica em $\mathrm{CO}_{2}$, daria origem a um líquido kamafugítico.

O caráter eminentemente explosivo do vulcanismo leucitítico da Formação Mata da Corda e sua associação com abundante fase gasosa rica em $\mathrm{CO}_{2}$ são aspectos indicativos da importância do $\mathrm{CO}_{2}$ na geração e no emplacement crustal desses magmas, enquanto que a abundância de nódulos duníticos parece indicar fases de fracionamento de olivina em câmaras magmáticas mais ou menos profundas.

E importante salientar que esses nódulos são composicional e texturalmente semelhantes a certos fácies de dunitos (olivina acumulados) integrantes de complexos ultramáficos alcalinos (Danni 1974), e aos encontrados em lavas do tipo olivina leucititos e analcimitos (Moraes 1984, Danni 1985).

Por outro lado, a inexistência nas rochas estudadas tanto de nódulos como de xenocristais inequivocamente mantélicos, impede o reconhecimento do tipo de manto e dos processos geodinâmicos que operaram na época da geração do olivina leucitito de Pântano.

A ocorrência de focos vulcânicos de filiação lamproítica e kimberlítica na área torna a província do Alto Paranaíba um cenário ímpar para as investigações das relações petrogenéticas entre estas suítes vulcânicas. Neste contexto, assume grande significação a investigação da origem dos diamantes encontrados nas aluviões da região vis à vis os distintos pulsos vulcânicos envolvidos na evolução magmática da província.

Agradecimentos O nosso reconhecimento à Companhia Brasileira de Metalurgia e Mineração (CBMM), na pessoa do geólogo B. Riffel, pelas determinações em microscopia eletrônica, ao professor H. Grossi Sad, pela doação da amostra do leucitito de Sacramento e ao geólogo G. Gonzaga, pela troca de idéias no campo.

\section{REFERÊNCIAS BIBLIOGRÁFICAS}

ALIBERT, C.; ALBAREDE, F. 1988. Relationships between mineralogical, chemical and isotopic properties of some North American Kimberlites. Jour. Geoph. Res., 93 (B7):7643-7671.

BARBOSA, O.; BRAUN, O.P.G.; DYER, R.C.; CUNHA C. 1970. Geologia da região do Triângulo Mineiro. Rio de Janeiro, DNPM/DPFM. 140p. (Boi. 13).

BARTON, M. 1979. A comparative study of some minerals occurring in the potassium-rich alkaline rocks of the Leucite Hills, the Vico Volcano, Western Italy and the Toro Ankole region, Uganda. Neues Jahrb Miner, Abh, 137:113-134.

DANNI, J.C.M. 1974. Geologic des Complexes Ultrabasiques alcalins de la region d'pora, Goiás, Brésü. Paris. 94p. (These, Universite Paris-Sud, Centre d'Orsay).

DANNI, J.C.M. 1985. Rochas da série kamafugítica na região de Amorinópolis, Goiás. NMG/SBG. In: Contribuições à Geologia e à Petrologia. Belo Horizonte, p. 5-13.

FOLEY, S.F. 1985. The oxidation state of lamproitic magmas Tschermaks. Min. Petr. Mitt. 34:217-238.

FOLEY, S.F.; VENTURELLI, B.; GREEN, D.H.; TOSCANI, L. 1987. The ultrapotassic rocks: characteristics, classification and constrains for petrogenetic models. Earth Sci. Rev., v.24:81-134.

GONZAGA, G. \& TOMPKINS, L. 1988 Geologia do diamante no Brasil. In: Principais depósitos minerais do Brasil. Brasília, DNPM. v.4.

GUIMARÃES D. 1955. Contribuição ao estudo dos tufos vulcânicos da Mata da Corda. Belo Horizonte, Inst. Tecnol. Ind.. 27p. (Bol. 18).

HASUI, Y., CORDANI, U.G. 1968. Idades Potássio Argônío de Rochas eroptivas mesozóicas do Oeste Mineiro e Sul de Goiás, In: CONG. BRAS. GEOL., 22. Belo Horizonte, 1968. Anais... Belo Horizonte, SBG. v. 1,p. 139-143.

HUGHES, C J. 1982. IgneousPetrology. Amsterdam, Elsevier. 551p

LADEIRA, E.A.; BRAUN, O.P.G.; CARDOSO, R.N.; HASUI, Y 1971. O Cretáceo em Minas Gerais. In: CONG. BRAS. GEOL., 25. São Paulo, 1971. Mesa Redonda... São Paulo, SBG. p. 15-31.

LADEIRA, E.A.; BRITO, O.E.A. 1968. Contribuição à geologia do Planalto da Mata da Corda. In: CONGR. BRÁS. GEOL., 22, Belo Horizonte. Anais... Belo Horizonte, SBG. v. 1, p. 181 -199.

LEONARD, O.H.; ULBRICH, M.N.C. 1987. Lamproitos de Presidente Olegário, Minas Gerais, In: REUNIÃO ANUAL DA SBPC, 36, Brasília. Resumos... Brasília.
MENZIES, M. MURTHY, V .R. 1980. Mantle metasomatism as a precursor to the genesis of alkaline magmas-isotopic evidences. Am. Jour. Sc., 280(A):622-638.

MORAES, L.C. 1984. Petrologia, estratigrafia e potencial diamantifero da suite vulcânica alcalina da região de Santo Antônio da Barra, Goiás. Brasília. 133p. (Dissertação de Mestrado, Depto. Geociências, UnB).

MORAES, L.C.; SEER, HJ.; KATTAR, S.S. 1987. Aspectos petroquímicos das rochas vulcânicas alcalinas cretáceas da porção meridional da Bacia Sanfranciscana, MG, In: CONG. BRAS. GEOQ., Porto Alegre. Anais... Porto Alegre, CBGq. v.1, p. 315-323.

MURTA, R.L.L. 1966. O vulcanito leucitítico de Sacramento Minas Gerais. Ouro Preto, Instituto de Geologia, EFMOP. p.13-20 (BoU(1)).

POUCLET, A. 1980. Contribution a Ia systematique des laves alcalines du rift de I'Afrique Centrale (Zaire-Uganda). Butt. Vol.,42:527-540.

S AHAMA, T.G. 1974. Potassium-rich alkaline rocks. In: SORENSEM H., ed. The alkaline Rocks. New York, Wiley and Sons, p.96-109.

SCHOBBENHAUS, C.; CAMPOS, D.A.; DERZE, G.R.; ASMUS, H.E. 1984. Geologia do Brasil. Brasília, MME/DNPM. 501p.

SEER, HJ.; MORAES, L.C. 1988. Estudo petrográfico das rochas ígneas da região de Lagoa Formosa, MG. Rev. Bras. Geoc. 18(2):134-140.

SVISERO, D.P.; HASUI, Y.; DRUMOND, D. 1979. Geologia de kimberlitos do Alto Paranaíba, Minas Gerais. Min. e Metal., 406:34-38.

SVISERO, D.P ; MEYER, O.A.H; HARALYI, N.L.E. HASUI, Y. 1984. A note on the geology of some Brasilian kimberlites. Jour Geol. 92:331-338.

TOMPKINS, L.A. \& GONZAGA, G.M. 1989. Diamonds in Brazil and a porposed model for the origin and distribution of diamonds in the Coromandel region. Minas Gerais, Brazil. Economic Geol. $84: 599-602$.

MANUSCRITO A627

Recebido em 27 de outubro de 1989 Revisão do autor em 9 de marco de 1990 Revisão aceita em 15 de março de 1990 